\title{
The Cone Evasion Walk test: Reliability and validity in acute stroke
}

Hanna Sjöholm, Staffan Hägg, Lars Nyberg, Bo Rolander and Ann-Sofi Kammerlind

The self-archived postprint version of this journal article is available at Linköping University Institutional Repository (DiVA):

http:// urn.kb.se/ resolve?urn=urn:nbn:se:liu:diva-156015

N.B.: When citing this work, cite the original publication.

Sjöholm, H., Hägg, S., Nyberg, L., Rolander, Bo, Kammerlind, A., (2019), The Cone Evasion Walk test: Reliability and validity in acute stroke, Physiotherapy Research International, 24(1), e1744.

https:// doi.org/ 10.1002/ pri.1744

Original publication available at:

https:// doi.org/ 10.1002/ pri.1744

Copyright: J ohn Wiley and Sons

http:// www.wiley.com/ 


\title{
The Cone Evasion Walk test: Reliability and validity in acute stroke
}

Short running title: Cone Evasion Walk: Reliability and validity

Hanna Sjöholm ${ }^{1}$, Staffan Hägg ${ }^{2}$, Lars Nyberg ${ }^{3}$, Bo Rolander ${ }^{4}$, Ann-Sofi Kammerlind ${ }^{2}$

1 Rehabilitation Centre, Region Jönköping County, Jönköping and Department of Medical and Health Sciences, Linköping University, Linköping, Sweden

2 Futurum, Region Jönköping County, Jönköping and Department of Medical and Health Sciences, Linköping University, Linköping, Sweden

3Department of Health Sciences, Luleå University of Technology, Luleå, Sweden

4 Futurum, Region Jönköping County, Jönköping, Sweden

This document is the Accepted Manuscript version of a Published Work that appeared in final form in Physiother Res Int. 2019;24(1):e1744. doi: 10.1002/pri.1744

\begin{abstract}
Objective: To estimate the reliability and validity of the Cone Evasion Walk test (CEW), a new test assessing the ability to evade obstacles, in people with acute stroke.
\end{abstract}

Methods: To estimate the reliability of the CEW, video recordings of 20 people with acute stroke performing the test were assessed by 10 physiotherapists on two occasions, resulting in a total of 400 ratings. Patients performed the CEW ( $n=221)$, Functional Ambulation Classification (FAC; $n=204$ ), Timed Up \& Go (TUG; $n=173$ ), TUG cognitive (TUG-cog; $n=139$ ), Serial 7s attention task from the Montreal Cognitive Assessment (MoCA-S7; $n=127$ ) and the Star Cancellation Test (SCT; $n=151)$. These tests and side of lesion $(n=143)$ were used to examine construct validity. The predictive validity was evaluated in relation to falls during the following 6 months $(n=203)$.

Results: The intra-class correlation coefficients for intrarater and interrater reliability were 0.88-0.98. For validity, there were significant correlations between the CEW and FAC $\left(r_{s}=-0.67\right)$, TUG $\left(r_{s}=0.45\right)$, MoCA-S7 $\left(r_{s}=-0.36\right)$ and SCT total score $\left(r_{s}=-0.36\right)$. There was a significant correlation between the number of cones touched on the left side and the proportion of cancelled stars on the left $\left(\mathrm{r}_{\mathrm{s}}=-0.23\right)$ and right $\left(\mathrm{r}_{\mathrm{s}}=0.23\right)$ side in the SCT. Among right hemisphere stroke participants $(n=79)$, significantly more persons hit cones on the left side $(n=25)$ than the right side $(n=8)$, whereas among those with a left hemisphere stroke $(n=64)$ significantly more persons hit cones on the right side $(n=11)$ than the left $(n=3)$. Cox regression showed that participants who touched four to eight cones had an increased risk of falls over time (Hazard ratio 2.11,95\% CI [1.07-4.17]) compared with those who touched none.

Conclusion: The new CEW test was reliable and valid in assessing the ability to evade obstacles while walking and to predict falls in patients with acute stroke.

Keywords: accidental falls, attention, stroke, walking 


\section{INTRODUCTION}

Older persons frequently fall and risk being injured, particularly after stroke. Incidence rates between 1.3-6.5 falls per person-year have been reported in people with stroke (Weerdesteyn, de Niet, van Duijnhoven, \& Geurts, 2008). Stroke can cause a variety of dysfunctions, such as impaired gait (Phan, Blennerhassett, Lythgo, Dite, \& Morris, 2013), attention deficits (Hyndman, Pickering, \& Ashburn, 2008), postural instability (Peurala, Könönen, Pitkänen, Sivenius, \& Tarkka, 2007), and impaired ability to avoid obstacles while walking (Ng et al., 2017). Van Swigchem, van Duijnhoven, den Boer, Geurts and Weerdesteyn (2013) assessed obstacle avoidance during walking. The healthy controls were successful in $97 \%$ of the trials and the people with stroke in $30 \%$. Physical exercise can improve the ability to negotiate

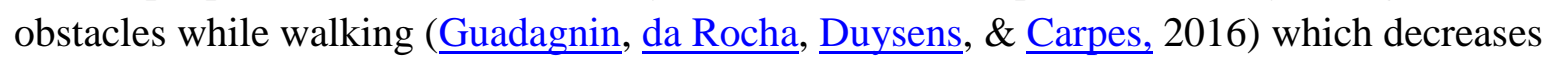
the fall incidence (Weerdesteyn et al, 2006). Compared with controls, people with stroke have slower muscular reactivity to balance perturbations (de Kam, Roelofs, Bruijnes, Geurts, \& Weerdesteyn, 2017) which increases the risk of falling (Marigold \& Eng, 2006).

People with stroke often demonstrate significant reductions in motor performance during gait activities with an added attention-demanding task (Plummer et al., 2013). A few tests assess the cognitive load to gait control by a dual task. The Stops walking when talking observation (Lundin-Olsson, Nyberg, \& Gustafson, 1997) and the Timed Up \& Go test with an added cognitive task (TUG-cog) (Shumway-Cook, Brauer, \& Woollacott, 2000) assesses the ability to simultaneously walk and answer a question or walk and perform an added cognitive task, which can be used to identify fallers (Beauchet et al, 2009; Hofheinz \& Mibs, 2016) . There are a few tests assessing walking with the attentional and proactive gait control demanding task of negotiating and crossing obstacles (Punt et al, 2017; Sun et al, 2010; van Swigchem et al, 2013; Taylor \& Gunther, 1997), but these tests cannot be performed when walking aids are used. We developed the Cone Evasion Walk test (CEW) to assess fall risk by the ability to evade obstacles, an activity classified with the ICF-code $\mathrm{d} 455$ which requires attentional (ICF-code b140), perceptual (ICF-code b156), seeing (ICF-code b210) and several neuromusculoskeletal and movement related functions (ICF-codes 710-799). This test can be performed with or without a walking aid and to the best of our knowledge no such test has previously been published. It is of importance to develop reliable and valid assessments of this ability for stroke patients (Streiner \& Norman, 2015; Aravind \& Lamontagne, 2017) and such assessments can be used to guide treatment, and identify improvements over time. The aim of the present study was to estimate the intrarater and interrater reliability and the construct and predictive validity of the CEW, a new test assessing fall risk by the ability to evade obstacles, in people with acute stroke.

\section{METHODS}

The CEW was developed by the first author based on the literature, clinical experience and in collaboration with patients and physiotherapists at the stroke unit at Ryhov County Hospital, Region Jönköping County, Sweden. The test procedures were pilot tested in two phases and face validity was established. In the first phase, systematic feedback was obtained from nine clinically active and experienced physiotherapists in the area of neurological disorders at two 
group meetings, where interpretations of the test instructions and assessment procedures were discussed and documented. In the second phase, four (of the nine previously mentioned) physiotherapists who worked at the stroke unit used the test in their clinical work over a 1year period and further reviewed the completeness and clarity of the instructions. The pilot testing resulted in modified instructions on how to administer the test and document the scores. The finalised manual and score sheet are presented in Appendix A.

\section{The Cone Evasion Walk test}

The CEW assesses the ability to twice walk a distance of $3 \mathrm{~m}$ between four cones without touching them. Subjects need to adapt their gait to avoid touching the cones (Figure 1). The cones are placed in relation to a temporary centre line. The distance between the cones and the centre line depends on whether the subject walks without a walking aid $(5 \mathrm{~cm})$, with crutches or a cane $(5 \mathrm{~cm})$, a walker $(25 \mathrm{~cm})$, or a walking table $(30 \mathrm{~cm})$. Subjects perform the test at a self-chosen speed with their ordinary walking aid and, if they need, support from someone while walking, which is recorded in the test assessment notes. Support should be restricted to what is necessary to prevent the subject from falling. The test leader records the total number of cones touched on each side (maximum 4), summarizes this into a total score (maximum 8), and records how many of the touches were made with the front or back of the walking aid, if one was used.

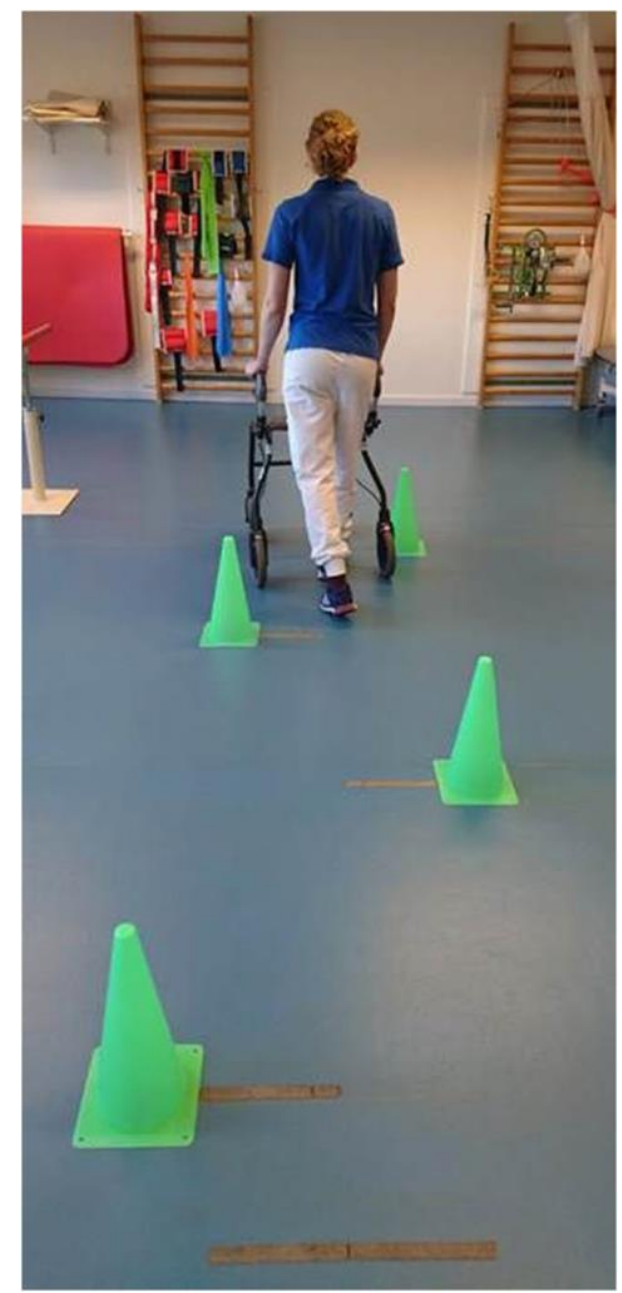

Figure 1. Cone Evasion Walk test 


\section{Reliability study}

Twenty participants were recruited consecutively from the stroke unit at Ryhov County Hospital, Region Jönköping County, Sweden. The inclusion criteria for participation in the study were stroke onset (ICD-code I61, I63 or I64) within two weeks before testing; the exclusion criteria were traumatic brain injuries, major orthopaedic problems, neurological problems other than stroke, no residual symptoms from the current stroke at the time of testing stated by physiotherapist, occupational therapist or physician, medical reasons for not being able to participate, or not being able to follow instructions considerably simpler than the test procedures.

One of the four physiotherapists working at the stroke unit conducted the test performance when 20 people with acute stroke performed CEW. Each one of the 20 participants performed CEW once and that performance was video-recorded. Ten physiotherapists assessed the 20 video recorded performances. Two weeks later the 10 physiotherapists assessed the 20 videorecorded performances a second time. Thus the study included 400 ratings.

A controlled and standardised situation was created where the assessments were carried out by the physiotherapists simultaneously. The physiotherapists received and read the manual in the beginning of each session, did not have access to their previous scores at the second session, could choose to watch the videos once or twice during each meeting, and were not allowed to discuss their scores with each other. The order in which the videos were observed was randomly determined and differed in the two sessions. All the physiotherapists had work experience in the field of neurology, median work experience 16 years, range 6-43 years and most of them had limited or no experience in using the test.

\section{Validity study}

The data for the validity analysis was derived from a multicentre study of fall prediction in acute stroke where results from several tests were collected. Three hundred participants were recruited consecutively from the stroke units at Ryhov County Hospital, Jönköping, University Hospital, Linköping, and Sunderby County Hospital, Luleå, Sweden. The inclusion criteria for participation were stroke onset (ICD-code I61, I63 or I64) within 2 weeks before testing and registered as a resident in the area for the respective hospital; the exclusion criteria were subarachnoid haemorrhage, stroke in the spinal cord, a potentially increased risk of impaired health from being asked to participate, or a professional interpreter needed to obtain informed consent.

The participants were tested by trained physiotherapists and occupational therapists working at the stroke-units, as soon as possible within 14 days from stroke onset. At discharge the participants were given a fall diary and were contacted by telephone once a month for six months to report potential falls. Family or nursing staff member reported falls when the participant could not and falls registered in the National Quality Registry for Preventative Care (Senior Alert) was also collected. A fall was defined as 'an unexpected event in which the participants come to rest on the ground, floor or lower level' (Lamb, Jorstad-Stein, Hauer, $\&$ Becker, 2005). Subarachnoid haemorrhage, stroke in the spinal cord and side of lesion were 
identified from medical imaging such as computer tomography and magnetic resonance imaging.

To analyse the construct validity, we selected tests from the multi-centre study that measure aspects of gait control, cognitive and perceptual functions that we expected to be related to CEW performance. The Functional Ambulation Classification (FAC) distinguishes six levels of walking ability on the basis of the amount of physical support needed at an ordinal scale (Holden, Gill, \& Magliozzi, 1986). The FAC has been shown to be reliable and valid in people with stroke (Mehrholz, Wagner, Rutte, Meissner, \& Pohl, 2007).

The TUG investigates basic mobility skills in interaction with the environment by measuring the time that a person takes to rise from a chair, walk $3 \mathrm{~m}$, turn around, walk back and sit down (Podsiadlo \& Richardson, 1991). The TUG has been demonstrated to be reliable and valid in people with stroke (Flansbjer, Holmback, Downham, Patten, \& Lexell, 2005). In the TUG-cog test, individuals are asked to complete the TUG while counting backwards (Shumway-Cook et al., 2000). The TUG-cog has been shown to be reliable in people with chronic stroke (Yang, He, \& Pang, 2016).

The Montreal Cognitive Assessment (MoCA) assesses multiple cognitive domains (Nasreddine et al., 2005) and its validity has been demonstrated in people with subacute stroke (Toglia, Fitzgerald, O’Dell, Mastrogiovanni, \& Lin, 2011). The Serial 7s attention task, scored by 1-3 scores at an ordinal scale, was selected for the validity analysis.

The Star Cancellation Test (SCT) detects the presence of unilateral spatial neglect by noting how many stars on a paper a person is able to detect. (Linden, Samuelsson, Skoog, \& Blomstrand, 2005). The SCT has been found to be reliable (Bailey, Riddoch, \& Crome, 2004) and valid (Bailey, Riddoch, \& Crome, 2000) in people with stroke.

Higher scores on the CEW, TUG and TUG-cog indicate lower ability, whereas higher scores on the FAC, MoCA-S7 and SCT indicate higher ability. Descriptive data about the participants were collected from journals and the Riks-Stroke Collaboration for both studies.

\section{Statistical analyses}

The medians and quartiles of the two test sessions were calculated for intrarater reliability and the overall percentage of agreement between the two test sessions was determined. To examine the consistency in scoring between the two test sessions, the intraclass correlation coefficient (ICC 2,1) (two-way random effect model, absolute agreement definition, single measure) with $95 \%$ confidence interval (CI) was used (Koo \& Li, 2016). For interrater reliability, the most common score for each participant was noted as well as the number of physiotherapists who gave that score. Next, the median and quartiles were calculated for how many physiotherapists had scored the most common score for all participants (Table 1). The interrater scoring consistency was examined using ICC 2,1. Correlations were investigated using Spearman's rank correlation coefficient, differences between groups by Fisher's exact test, and pairwise comparisons by Wilcoxon's test (back wheel/front wheel). The relationship 
between the CEW and falls and the number of days to the first fall incident was analysed by linear regression, and the ability of the CEW to predict falls was analysed by Cox regression. A correlation coefficient between 0 and 0.50 was considered as a poor correlation, 0.50 and 0.75 as moderate correlation, 0.75 and 0.90 as good correlation, and 0.90 and 1 as excellent correlation (Koo \& Li, 2016).

Table 1. Example of how the number of PTs scoring the most common value was calculated to assess the interrater reliability of the Cone Evasion Walk test in acute stroke patients $(n=20)$

\begin{tabular}{|c|c|c|c|c|c|c|c|c|c|c|c|}
\hline Patient & PT1 & PT2 & PT3 & PT4 & PT5 & PT6 & PT7 & PT8 & PT9 & PT10 & $\begin{array}{l}\text { Number of PTs scoring the } \\
\text { most common value }\end{array}$ \\
\hline 1 & 0 & 0 & 0 & 0 & 0 & 0 & 0 & 0 & 0 & 0 & 10 \\
\hline 2 & 2 & 2 & 2 & 2 & 2 & 1 & 2 & 2 & 2 & 2 & 9 \\
\hline 3 & 4 & 4 & 4 & 4 & 4 & 4 & 4 & 4 & 4 & 4 & 10 \\
\hline - & - & - & - & - & - & - & - & - & - & • & - \\
\hline 20 & • & • & • & - & • & • & • & • & • & $\dot{\bullet}$ & $\dot{\bullet}: 10(10-10)$ \\
\hline
\end{tabular}

PT $=$ physiotherapist $; \mathrm{q}=$ quartile.

In each validity analysis, participants who did not perform CEW and the other test on the same day were excluded. Participants with stroke in both hemispheres were excluded from the analysis when CEW performance was compared with the lesion location. When the CEW was analysed compared with falls, participants who did not perform the CEW or all of the 6monthly fall follow-ups were excluded. In SCT the proportion of cancelled stars was calculated by dividing the number of stars cancelled on one side by the total number of cancelled stars.

\section{RESULTS}

\section{Reliability study}

Twenty participants ( 7 women and 13 men) were included in the reliability study. Descriptive characteristics are given in Table 2. Fifteen persons (12 women and 3 men) were eligible for the study but did not participate: 12 did not agree to participate, 2 could not perform the assessments before hospital discharge due to practical reasons and one subject was included but the film quality was too poor to analyse.

When performing the CEW, 12 participants did not use walking aids, 5 used a walker and 3 used a walking table, including 1 participant who was supported by another person. One of the participants who used a walking aid did not touch the cones, but the others touched two to five cones. None of the participants who walked without an aid touched the cones. 
The ICCs for intra-rater reliability were good to excellent, $0.89-0.98$ and the overall percentage of agreement was $70-96 \%$ for the total scores and the four sub-scores, indicating that the physiotherapists evaluated the videos with high agreement (Table 3). For inter-rater reliability, the ICCs were also good to excellent, $0.88-0.97$, and the medians indicated that 910 out of 10 physiotherapists gave the same score (Table 4).

Table 2. Background characteristics of study participants (reliability study $n=20$, validity study $n=221$ ) and the general stroke population in Sweden

\begin{tabular}{|c|c|c|c|}
\hline & $\begin{array}{l}\text { Study participants } \\
\text { Reliability study }\end{array}$ & $\begin{array}{l}\text { Study participants } \\
\text { Validity study }\end{array}$ & $\begin{array}{l}\text { General stroke } \\
\text { population* }\end{array}$ \\
\hline Age, years, mean (range) & $74(51-91)$ & $73(36-95)$ & 75 \\
\hline Sex, men/women, \% (n) & $65 / 35(13 / 7)$ & $57 / 43(127 / 94)$ & $53 / 47$ \\
\hline Living alone, yes/no, \% (n) & $53 / 47(10 / 9)^{* *}$ & $37 / 63(81 / 140)$ & $48 / 52$ \\
\hline ADL dependent before stroke onset, yes/no, $\%$ (n) & $5 / 95(1 / 18)^{* *}$ & $15 / 85(31 / 169)^{* * *}$ & $13 / 87$ \\
\hline First stroke, yes/no, \% (n) & $74 / 26(14 / 5)^{* *}$ & $78 / 22(169 / 47)^{* * *}$ & $78 / 22$ \\
\hline Days since stroke onset, median (range) & $5(1-13)$ & $4(0-14)$ & \\
\hline $\begin{array}{l}\text { Stroke type } \\
\text { Haemorrhage, \% (n) } \\
\text { Infarction, \% (n) } \\
\text { Not specified, \% (n) } \\
\text { Both, \% (n) }\end{array}$ & $\begin{array}{l}15(3) \\
70(14) \\
15(3) \\
0(0)\end{array}$ & $\begin{array}{l}8(18) \\
69(153) \\
20(44) \\
3(6)\end{array}$ & $\begin{array}{l}13 \\
86 \\
1\end{array}$ \\
\hline $\begin{array}{l}\text { Stroke location**** } \\
\text { Right, } \mathrm{n} \\
\text { Left, } \mathrm{n} \\
\text { Brainstem, } \mathrm{n} \\
\text { Cerebellum, } \mathrm{n} \\
\text { Not specified, } \mathrm{n} \\
\end{array}$ & $\begin{array}{l}12 \\
1 \\
3 \\
2 \\
3 \\
\end{array}$ & $\begin{array}{l}87 \\
72 \\
12 \\
22 \\
44\end{array}$ & \\
\hline Walking aid, yes/no, \% (n) & $40 / 60(8 / 12)$ & $38 / 62(84 / 137)$ & \\
\hline NIHSS, median (range) & $2(0-11)^{* *}$ & $3(0-21)^{* * *}$ & $3(0-42)$ \\
\hline $\begin{array}{l}\text { Pares***** } \\
\text { Right side, } \%(\mathrm{n}) \\
\text { Left side, } \%(\mathrm{n}) \\
\text { No pares, } \%(\mathrm{n}) \\
\text { Both, } \%(\mathrm{n}) \\
\text { Missing data } \\
\end{array}$ & $\begin{array}{l}20(4) \\
65(13) \\
15(3)\end{array}$ & $\begin{array}{l}7(17) \\
14(30) \\
73(162) \\
5(11) \\
0(1)\end{array}$ & \\
\hline $\begin{array}{l}\text { Cognitive impairment (journal) } * * * * *, \text { yes/no, \% (n) } \\
\text { Cognitive impairment (MoCA) } * * * * *, \text { yes/no, \% (n) } \\
\text { Missing data }\end{array}$ & $50 / 50(10 / 10)$ & $\begin{array}{l}68 / 29(151 / 64) \\
3(6)\end{array}$ & \\
\hline $\begin{array}{l}\text { Impaired attention to one side*****, yes/no, \% (n) } \\
\text { Neglect*****, yes/no, \% (n) } \\
\text { Missing data }\end{array}$ & $15 / 85(3 / 17)$ & $\begin{array}{l}7 / 90(15 / 200) \\
3(6)\end{array}$ & \\
\hline Cone Evasion Walk test, median (range) & $0(0-5)$ & $0(0-7)$ & \\
\hline
\end{tabular}

* Data collected from Riks-strokes Årsrapport 2016 (Riks-stroke Collaboration 2017)

** Data was available for 19 participants

*** Data was available for 200 participants regarding ADL, 215 participants regarding first stroke and 156 participants regarding NIHSS **** Some patients had more than one stroke location

****** In the reliability study data about pares, cognitive impairment, and impaired attention to one side was collected from the journals. In the validity study pares was determined from NIHSS, cognitive impairment results $<26$ scores at the MoCA, and neglect results $<44$ from Star Cancellation Test.

$\mathrm{ADL}=$ activities of daily living; MoCA = Montreal Cognitive Assessment; NIHSS = National Institutes of Health Stroke Scale 


\section{Validity study}

The validity study included 221 participants (94 women and 127 men) from the multi-centre study. Descriptive characteristics are given in Table 2. There were 178 persons (90 women and 88 men) who were eligible for the study but did not participate: $146 \mathrm{did}$ not agree to participate, no physiotherapist was available to perform the assessments for 31 persons before hospital discharge and 1 was not asked to participate within 14 days after stroke onset.

Table 3. Intra-rater reliability for the Cone Evasion Walk test in acute stroke patients $(n=20)$

\begin{tabular}{|c|c|c|c|c|}
\hline Variable & $\begin{array}{l}\text { First test } \\
\text { session, } \\
\text { median (q1-q3) }\end{array}$ & $\begin{array}{l}\text { Second test } \\
\text { session, } \\
\text { median (q1-q3) }\end{array}$ & $\begin{array}{l}\text { Overall } \\
\text { agreement }(\%)\end{array}$ & ICC $(95 \% \mathrm{CI})$ \\
\hline Total number of cone touches & $0(0-2)$ & $0(0-2)$ & 90 & $0.98(0.97-0.98)$ \\
\hline $\begin{array}{l}\text { Number of cone touches on the right } \\
\text { side }\end{array}$ & $0(0-0)$ & $0(0-0)$ & 93 & $0.89(0.86-0.92)$ \\
\hline Number of cone touches on the left side & $0(0-2)$ & $0(0-2)$ & 96 & $0.98(0.98-0.99)$ \\
\hline $\begin{array}{l}\text { Number of cone touches with the front } \\
\text { of the walking aid }\end{array}$ & $0(0-3)$ & $1(0-3)$ & 83 & $0.94(0.91-0.96)$ \\
\hline $\begin{array}{l}\text { Number of cone touches with the back } \\
\text { of the walking aid }\end{array}$ & $2(0-2)$ & $2(0-2)$ & 70 & $0.91(0.86-0.94)$ \\
\hline
\end{tabular}

$\mathrm{CI}=$ confidence interval $; \mathrm{ICC}=$ intra-class correlation coefficients; $\mathrm{q}=$ quartile.

Table 4. Inter-rater reliability for Cone Evasion Walk test in acute stroke patients $(n=20)$

\begin{tabular}{|c|c|c|}
\hline Variable & $\begin{array}{l}\text { Number of PTs scoring the most } \\
\text { common value, median }(\mathrm{q} 1-\mathrm{q} 3)^{*}\end{array}$ & $\operatorname{ICC}(95 \% \mathrm{CI})$ \\
\hline Total number of cone touches* & $10(10-10)^{*}$ & $0.96(0.94-0.98)$ \\
\hline Number of cone touches on the right side & $10(10-10)$ & $0.92(0.86-0.96)$ \\
\hline Number of cone touches on the left side & $10(10-10)$ & $0.97(0.95-0.99)$ \\
\hline $\begin{array}{l}\text { Number of cone touches with the front of } \\
\text { the walking aid }\end{array}$ & $10(7-10)$ & $0.93(0.85-0.98)$ \\
\hline $\begin{array}{l}\text { Number of cone touches with the back of } \\
\text { the walking aid }\end{array}$ & $9(6-10)$ & $0.88(0.74-0.97)$ \\
\hline
\end{tabular}


When performing the CEW, 137 participants did not use a walking aid but two were supported by another person, 58 used a walker, 23 used a walking table, and three used a cane or crutches. Sixteen of the participants who did not use a walking aid and 47 who did use a walking aid touched one or several cones. Among participants using walkers or walking tables significantly more cones were touched with the back wheels compared to the front wheels $(\mathrm{p}=0.02)$. There was a floor effect on the $\mathrm{CEW}$ with $71 \%$ of the participants hitting no cones (Table 5).

Table 5. Distribution of the number of cone touches on the Cone Evasion Walk test in acute stroke patients $(n=221)$

\begin{tabular}{lll}
\hline Number of cone touches & Frequency & Percent \\
\hline 0 & 158 & 71 \\
1 & 13 & 6 \\
2 & 12 & 5 \\
3 & 8 & 4 \\
4 & 16 & 7 \\
5 & 9 & 4 \\
6 & 3 & 1 \\
7 & 2 & 1 \\
8 & 0 & 0 \\
\hline
\end{tabular}

Table 6. Construct validity of the Cone Evasion Walk test in acute stroke patients

\begin{tabular}{ll}
\hline Variable & $\mathrm{r}_{\mathrm{S}}$ \\
\hline Functional Ambulation Classification $(n=204)$ & $-0.67^{*}$ \\
Timed Up and Go test $(n=173)$ & $0.45^{*}$ \\
Timed Up and Go test cognitive $(n=139)$ & $-0.04 \mathrm{~ns}$ \\
Montreal Cognitive Assessment Serial $7 \mathrm{~s}(n=127)$ & $-0.36^{*}$ \\
Star Cancellation Test $(n=151)$ & $-0.36^{*}$ \\
\hline
\end{tabular}

$*=\mathrm{p}<0.05 ; \mathrm{ns}=$ not significant

The total number of cones touched in the CEW was significantly but poorly to moderately correlated with scores on the FAC, TUG, MoCA-S7 and SCT total score. There was no significant correlation between the CEW and TUG-cog (Table 6).

Among those who had a right hemisphere stroke $(n=79)$, significantly more participants hit cones on the left side $(n=25)$ than the right $(n=8)(\mathrm{p}=0.001)$. Among those who had a left 
hemisphere stroke ( $n=64)$, significantly more participants hit cones on the right side $(n=11)$ than the left $(n=3)(\mathrm{p}<0.01)$. The total number of cones touched on the left side showed a significant, poor, correlation with the proportion of stars cancelled on the left side $\left(r_{s}=-0.23\right.$, $\mathrm{p}<0.05$ ), but a significant, poor, correlation with the proportion of stars cancelled on the right side $\left(\mathrm{r}_{\mathrm{s}}=0.23, \mathrm{p}<0.05\right)$ There was no significant correlation between the number of cones touched on the right side and the proportion of stars cancelled on either the left $\left(r_{s}=0.06 \mathrm{~ns}\right)$ or the right $\left(\mathrm{r}_{\mathrm{s}}=-0.06 \mathrm{~ns}\right)$.

Among the 221 participants included in the predictive validity analysis, 83 participants fell and 138 did not. There was a significant, poor correlation between the number of cones touched and the number of falls $(\mathrm{R}=0.18, \mathrm{p}=0.01)$. When only those who touched the cones $(n=56)$ were included in the analysis, the correlation became more robust $(R=0.31, p=0.02)$. There was a poor, negative correlation between the number of cones touched and the number of days that passed from admission to the first fall incident $(\mathrm{R}=-0.28, \mathrm{p}=0.02)$. Cox regression showed that the risk of falls over time more than doubled for participants who touched four to eight cones compared with those who touched none (Hazard ratio 2.11, 95\% CI 1.07-4.17, $\mathrm{p}=0.03$ ) (Figure 2).

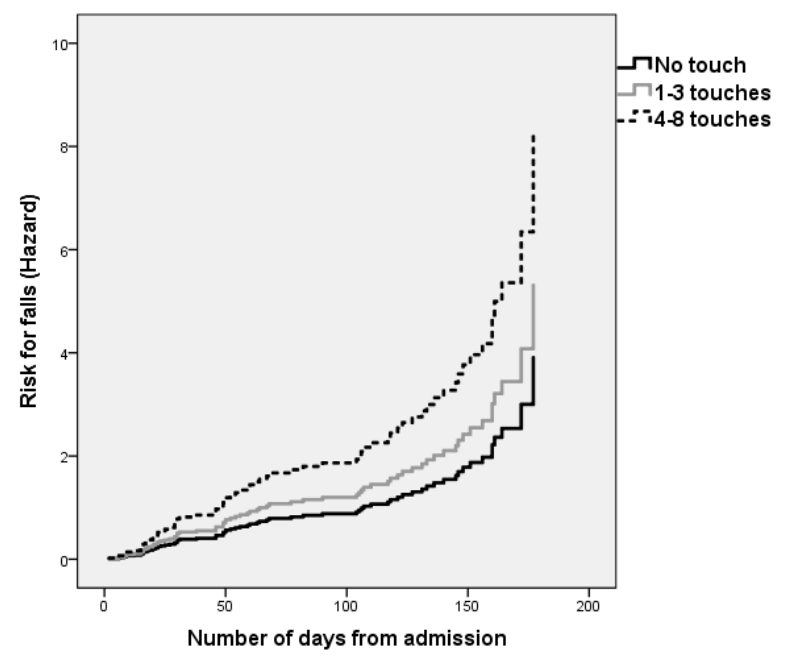

Figure 2. Risk of falls based on the results of the Cone Evasion Walk test in acute stroke patients $(n=203)$ analysed by Cox regression.

\section{DISCUSSION}

We developed the CEW to assess fall risk by the ability to evade obstacles while walking. The results of this study show that the test predicts falls and can be used to reliably assess activity in people with acute stroke. Other attention demanding walking tests, such as the TUG-cog (Shumway-Cook et al., 2000) and Stops walking when talking observation (Lundin-Olsson et al., 1997), assess dual task sensitivity in walking, whereas the CEW is designed to assess 
proactive gait control in response to an environmental challenge, which is common in everyday life. The TUG assesses gait control in relation to the environment, but a novel aspect of the CEW is that it may provide spatial information about which side is more vulnerable while walking, as both the number and locations of cone touches are noted.

The CEW assesses the ability to evade obstacles while walking at a self-chosen speed and with an ordinary walking aid since we believe this best mirrors daily life behaviour. The test score is not affected by the time needed to complete the test despite that time also reflects the functional performance. Time and touches would be difficult to combine into one score in a relevant way, and in most daily life situations it is possible to choose how fast to gait. The distances from the cones to the centre line were determined so that the margin was approximately the same regardless of the type of walking aid. The CEW is inexpensive and easy to administer. When the placements of the cones are marked on the floor, it takes less than five minutes to set up and complete.

The purpose was to investigate reliability and validity of CEW in people with acute stroke, and therefore people with stroke were recruited consecutively despite function and use of walking aid. Sometimes the medical diagnosis is delayed, which is why the criteria for participating in the study were a diagnosis of stroke and onset of symptoms within 14 days. Douiri, Rudd, \& Wolfe (2013) reported disturbed cognitive performance in 22\% of persons at 3 months post-stroke. We designed the study to be as representative of the average population as possible; therefore, people with cognitive dysfunction were included. As long as the participants had not failed on tasks with simpler instructions they were asked to perform the tests.

The performance of people with stroke varies considerably over time for example because of changes in fatigue and improved function. To account for this variability, we assessed intraobserver reliability by videotaping participants and requesting two separate test scores from the observing physiotherapists, as recommended by Streiner and Norman (2015). To reduce the risk that the first outcome could influence the second outcome due to physiotherapists remembering their previous scoring, at least 2 weeks passed between the first and second assessments (Streiner \& Norman, 2015). In reality, the test can be repeated if it is hard to judge the subject's performance; therefore, the physiotherapists in our study were given the opportunity to watch the test videos twice at each meeting.

To ensure the results were comparable with those of similar studies, we used an established definition of fall recommended by an international group of experts (Lamb et al., 2005), as well as their recommendation to use both a falls diary and regular phone calls. Because the multi-centre study included a large test battery, not all of the participants had the strength to complete all of the tests on the same day. To account for daily changes, the correlation analysis was limited to participants who performed the tests on the same day. The correlation analysis regarding falls was assessed both with and without the day of test performance taken into account, with no effect on the result. 
The correlations between the CEW and the FAC, TUG, SCT and MoCA-S7 show that the CEW assesses many of the same abilities as those assessed by these tests. The gait is assessed in CEW, FAC and TUG, and CEW, SCT and MoCA-S7 assess attention to some extent. However, the poor to moderate correlation coefficients confirm the novel status of the CEW, which does not assess exactly the same functions as these tests. The results indicate that the CEW assesses both gait and attention, but from a different perspective than the TUG-cog, because the correlation between the two tests was not significant. Visuo-spatial neglect is more common following a right hemisphere than a left hemisphere stroke (Li \& Malhotra, 2015). This might explain why there was a significant correlation between the proportion of cancelled stars in the SCT and the number of cones touched on the left, but not the right side, in the CEW.

The CEW has a floor-effect in people with acute stroke. The proportion of participants touching cones was higher among persons using walking aids. The later can be expected to have impaired motor control and therefore a tendency to touch more cones. It also seems reasonable that people can more easily adapt their gait to evade obstacles when they only have to pay attention to the body rather than the body and something else, like an additional walking aid. It has for example been shown that people who perform the TUG test get better results if they don't simultaneously carry and pay attention to a glass of water (Hofheinz \& Schusterschitz, 2010).

Among those who did not touch any cones $77 \%$ walked without walking aids. The correlation between the CEW and falls was stronger when only those who touched cones were included in the analysis. Participants who did not touch any cones had no severe problems evading obstacles while walking, but might have other impairments that increase the risk of falls. This may explain the increased correlation when their data were excluded. There is a lack of instruments assessing the ability to evade objects while walking with walking aids and the CEW is especially useful in that particular group of patients.

Repetition of the test over time can identify changes in obstacle avoidance performance regarding the number of touches, and the proportion of touches made by a front or back wheel. In this study significantly more cones were touched with the back wheels, which indicate that it is more difficult to pay attention to those.

Limitations of this study are the lack of information about whether the test was performed with or without shoes and the scarce assessments of functions that might have influenced the test result. It could be expected that for example impaired balance, physical condition, proprioception, muscle function, apraxia, vision, attention, perception and joint mobility would influence performance of the CEW. The monthly follow-ups focusing on falls might have made participants more aware of the risk of falling. This awareness might have led to a reduced number of fall incidents.

In clinical applications, test performances are not usually assessed by video, as in the reliability study. This introduces a potential difference between the study and the clinical 12 
context. For example, in a clinical testing situation, the assessor is able to move and observe the subject from different angles, which is impossible when watching videos. Another aspect that may affect the results is the assessor's professional and clinical experience in neurology and test protocols which varied among the physiotherapists in this study. We wanted the test to be reliable regardless of factors such as viewing angle and assessor experience, and the results confirmed that the test was reliable even under these circumstances.

Assessing intra- and inter-rater reliability based on videos is advantageous when studying instrumental aspects of intra-observer reliability, as the performance of subjects with acute stroke varies considerably over time. Further research is needed to evaluate the test-retest reliability and also the reliability and validity for each walking aid separately.

In conclusion, we developed a new test for assessing fall risk by the ability to evade obstacles while walking and demonstrated its good reliability and validity in people with acute stroke. The intra- and inter-rater reliability of the test was good to excellent (ICC 0.88-0.98), and the results showed an expected significant poor to moderate correlation $\left(\mathrm{r}_{\mathrm{s}} 0.36-0.67\right)$ with other tests such as the FAC, TUG, MoCA-S7 and SCT. Participants touched significantly more cones on the side that was opposite to the side of their lesion. The CEW had a good ability to predict falls.

\section{IMPLICATIONS FOR PHYSIOTHERAPY PRACTICE}

The results of this study show that the CEW test predicts falls and can be used to reliably assess the ability of people with acute stroke to evade obstacles while walking. The test complements the existing range of assessments for subjects with impaired attention and proactive gait control.

\section{ACKNOWLEDGEMENTS}

The authors would like to acknowledge everyone who contributed to the study by watching the videos or commenting on the assessments. The authors thank Sebastian Gustafsson, Jeanette Johansson, Anna Olin, Josefin Rönnerfors, Christina Sellin, and Matilda Stjärnebring for help with data collection. The collected information about falls was complemented by falls registered in the National Quality Registry for Preventative Care (Senior Alert). The descriptive data was complemented with data from Riks-Stroke Collaboration. This study was supported by grants from Futurum, Region Jönköping County, The Swedish Stroke National Association, and Medical Research Council of Southeast Sweden.

\section{ETHICAL CONSIDERATIONS}

Informed consent was obtained from all participants. The study was performed in accordance with the Declaration of Helsinki and was approved by the Regional Ethical Review Board in Linköping (dnr 2013/14-31, 2013/132-32, 2013/291-32, 2017/577-32, 2017/578-32).

\section{FUNDING INFORMATION}

Medical Research Council of Southeast Sweden; The Swedish Stroke Association; Futurum Region Jönköping County. 


\section{REFERENCES}

Aravind, G., \& Lamontagne, A. (2017). Effect of visuospatial neglect on spatial navigation and heading after stroke. Annals of Physical and Rehabilitation Medicine, S1877-0657(17), 30075-30071. https://doi.org/10.1016/j.rehab.2017.05.002 (Epub ahead of print)

Bailey, M. J., Riddoch, M. J., \& Crome, P. (2000). Evaluation of a test battery for hemineglect in elderly stroke patients for use by therapists in clinical practice. NeuroRehabilitation, 14, 139-150.

Bailey, M. J., Riddoch, M. J., \& Crome, P. (2004). Test-retest stability of three tests for unilateral visual neglect in patients with stroke: Star Cancellation, Line Bisection, and the Baking Tray Task. Neuropsychological Rehabilitation, 14(4), 403-419.

Beauchet, O., Annweiler, C., Dubost, V., Allali, G., Kressig, R. W., Bridenbaugh, S., ... Herrmann, F. R. (2009). Stops walking when talking: A predictor of falls in older adults? European Journal of Neurology, 16, 786-795. https://doi.org/10.1111/j.14681331.2009.02612.x

Douiri, A., Rudd, A. G., \& Wolfe, C. D. (2013). Prevalence of poststroke cognitive impairment: South London StrokeRegister 1995-2010. Stroke, 44, 138-145. https://doi.org/10.1161/STROKEAHA.112.670844

Flansbjer, U. B., Holmback, A. M., Downham, D., Patten, C., \& Lexell, J. (2005). Reliability of gait performance tests in men and women with hemiparesis after stroke. Journal of Rehabilitation Medicine, 37, 75-82. https://doi.org/10.1080/16501970410017215

Guadagnin, E. C., da Rocha, E. S., Duysens, J., \& Carpes, F. P. (2016). Does physical exercise improve obstacle negotiation in the elderly? A systematic review. Archives of Gerontology and Geriatrics, 64, 138-145. https://doi.org/10.1016/j.archger.2016.02.008

Hofheinz, M., \& Mibs, M. (2016). The prognostic validity of the Timed Up and Go test with a dual task for predicting the risk of falls in the elderly. Gerontology and Geriatric Medicine, 2. 2333721416637798. https://doi.org/10.1177/2333721416637798

Hofheinz, M., \& Schusterschitz, C. (2010). Dual task interference in estimating the risk of falls and measuring change: A comparative, psychometric study of four measurements. Clinical Rehabilitation, 24, 831-842. https://doi.org/10.1177/0269215510367993

Holden, M., Gill, K. M., \& Magliozzi, M. R. (1986). Gait assessment for neurologically impaired patients: Standards for outcome assessment. Physical Therapy, 66, 1530-1539.

Hyndman, D., Pickering, R. M., \& Ashburn, A. (2008). The influence of attention deficits on functional recovery post stroke during the first 12 months after discharge from hospital. Journal of Neurology, Neurosurgery and Psychiatry, 79, 656-663.

de Kam, D., Roelofs, J. M. B., Bruijnes, A. K. B. D., Geurts, A. C. H., \& Weerdesteyn, V. (2017). The next step in understanding impaired reactive balance control in people with 
stroke: The role of defective early automatic postural responses. Neurorehabilitation and Neural Repair, 31, 708-716. https://doi.org/10.1177/1545968317718267

Koo, T. K., \& Li, M. Y. (2016). A guideline of selecting and reporting intraclass correlation coefficients for reliability research. Journal of Chiropractic Medicine, 15, 155-163.

Lamb, S. E., Jorstad-Stein, E. C., Hauer, K., \& Becker, C. (2005). Development of a common outcome data set for fall injury prevention trials: The Prevention of Falls Network Europe consensus. Journal of the American Geriatrics Society, 53, 1618-1622.

Li, K., \& Malhotra, P. A. (2015). Spatial neglect. Practical Neurology, 15, 333-339. https://doi.org/10.1136/practneurol-2015-001115

Linden, T., Samuelsson, H., Skoog, I., \& Blomstrand, C. (2005). Visual neglect and cognitive impairment in elderly patients late after stroke. Acta Neurologica Scandinavica, 111, 163168.

Lundin-Olsson, L., Nyberg, L., \& Gustafson, Y. (1997). "Stops walking when talking” as a predictor of falls in elderly people. Lancet, 349, 617. https://doi.org/10.1016/S01406736(97)24009-2

Marigold, D. S., \& Eng, J. J. (2006). Altered timing of postural reflexes contributes to falling in persons with chronic stroke. Experimental Brain Research, 171, 459-468.

https://doi.org/10.1007/s00221-005-0293-6

Mehrholz, J., Wagner, K., Rutte, K., Meissner, D., \& Pohl, M. (2007). Predictive validity and responsiveness of the Functional Ambulation Category in hemiparetic patients after stroke. Archives of Physical Medicine and Rehabilitation, 88, 1314-1319.

Nasreddine, Z. S., Phillips, N. A., Bediriam, V., Charbonneau, S., Whitehead, V., Collin, I., ... Chertkow, H. (2005). The Montreal Cognitive Assessment, MoCA: A brief screening tool for mild cognitive impairment. Journal of the American Geriatrics Society, 53, 695-699.

Ng, S. S. M., Chan, S. C. L., Chan, A. K. Y., Chung, H. H. Y., Lee, N. K. W., Ngan, A. T. S., \& Tse, M. M. Y. (2017). Reliability and concurrent validity of standardized walking obstacle course test in people with stroke. Journal of Rehabilitation Medicine, 49, 705-714.

https://doi.org/10.2340/16501977-2265

Peurala, S. H., Könönen, P., Pitkänen, K., Sivenius, J., \& Tarkka, I. M. (2007). Postural instability in patients with chronic stroke. Restorative Neurology and Neuroscience, 25, 101108.

Phan, P. L., Blennerhassett, J. M., Lythgo, N., Dite, W., \& Morris, M. E. (2013). Over-ground walking on level and sloped surfaces in people with stroke compared to healthy matched adults. Disability and Rehabilitation, 35, 1302-1307.

https://doi.org/10.3109/09638288.2012.729646 
Plummer, P., Eskes, G., Wallace, S., Giuffrida, C., Fraas, M., Campbell, G., American Congress of Rehabilitation Medicine Stroke Networking Group Cognition Task, F (2013). Cognitive-motor interference during functional mobility after stroke: State of the science and implications for future research. Archives of Physical Medicine and Rehabilitation, 94, 25652574. e2566. https://doi.org/10.1016/j.apmr.2013.08.002

Podsiadlo, D., \& Richardson, S. (1991). The timed "Up \& Go": A test of basic functional mobility for frail elderly persons. Journal of the American Geriatrics Society, 39, 142-148.

Punt, M., Bruijn, S. M., Wittink, H., van de Port, I. G., Wubbels, G., \& van Dieën, J. H. (2017). Virtual obstacle crossing: Reliability and differences in stroke survivors who prospectively experienced falls or no falls. Gait \& Posture, 58, 533-538. https://doi.org/10.1016/j.gaitpost.2017.09.013

Shumway-Cook, A., Brauer, S., \& Woollacott, M. (2000). Predicting the probability for falls in community-dwelling older adults using the Timed Up \& Go Test. Physical Therapy, 80, 896-903.

Streiner, D. L., Norman, G. R., \& Cairney, J. (2015). Health measurement scales: A practical guide to their development and use (5th ed.). Oxford: Oxford University Press.

Sun, W., Watanabe, M., Hirota, C., Tanimoto, Y., Kono, R., Takasaki, K., \& Kono, K. (2010). Obstacle-negotiating gait and related physical measurement indicators for the community-dwelling elderly in Japan. Archives of Gerontology and Geriatrics, 50, e41-e45. https://doi.org/ 10.1016/j.archger.2009.01.016

van Swigchem, R., van Duijnhoven, H. J., den Boer, J., Geurts, A. C., \& Weerdesteyn, V. (2013). Deficits in motor response to avoid sudden obstacles during gait in functional walkers poststroke. Neurorehabilitation and Neural Repair, 27, 230-239. https://doi.org/ $10.1177 / 1545968312462070$

Taylor, M. J., \& Gunther, J. (1997). Standardized walking obstacle course: Reliability and validity of a functional measurement tool. Journal of Neurologic Physical Therapy, 21, 167.

Toglia, J., Fitzgerald, K. A., O'Dell, M. W., Mastrogiovanni, A. R., \& Lin, C. D. (2011). The Mini-Mental State Examination and Montreal Cognitive Assessment in persons with mild subacute stroke: Relationship to functional outcome. Archives of Physical Medicine and Rehabilitation, 92, 792-798. https://doi.org/10.1016/j.apmr.2010.12.034

Weerdesteyn, V., de Niet, M., van Duijnhoven, H. J., \& Geurts, A. C. (2008). Falls in individuals with stroke. Journal of Rehabilitation Research and Development, 45, 1195-1213.

Weerdesteyn, V., Riiken, H., Geurts, A. C., Smits-Engelsman, B. C., Mulder, T., \& Duyens, J. (2006). A five-week exercise program can reduce falls and improve obstacle avoidance in the elderly. Gerontology, 52, 131-141. 
Yang, L., He, C., \& Pang, M. Y. C. (2016). Reliability and validity of dual-task mobility assessments in people with chronic stroke. PLoS One, 11, e0147833.

https://doi.org/10.1371/journal.pone.0147833 


\section{Appendix:}

\section{The Cone Evasion Walk test (CEW)}

Preparations Read this part before placing the cones.

Place four cones spaced over a length of 3 metres as shown in the picture below.

The centres of the cones are placed $0.3 \mathrm{~m}$, $1.2 \mathrm{~m}, 2.1 \mathrm{~m}$, and $3 \mathrm{~m}$ from the starting line. The edge of the cone that is closest to the imagined centre line is placed at a spot that is $5 \mathrm{~cm}(\mathrm{~A}), 25 \mathrm{~cm}(\mathrm{~B})$, or $30 \mathrm{~cm}(\mathrm{C})$ away from the centre line.

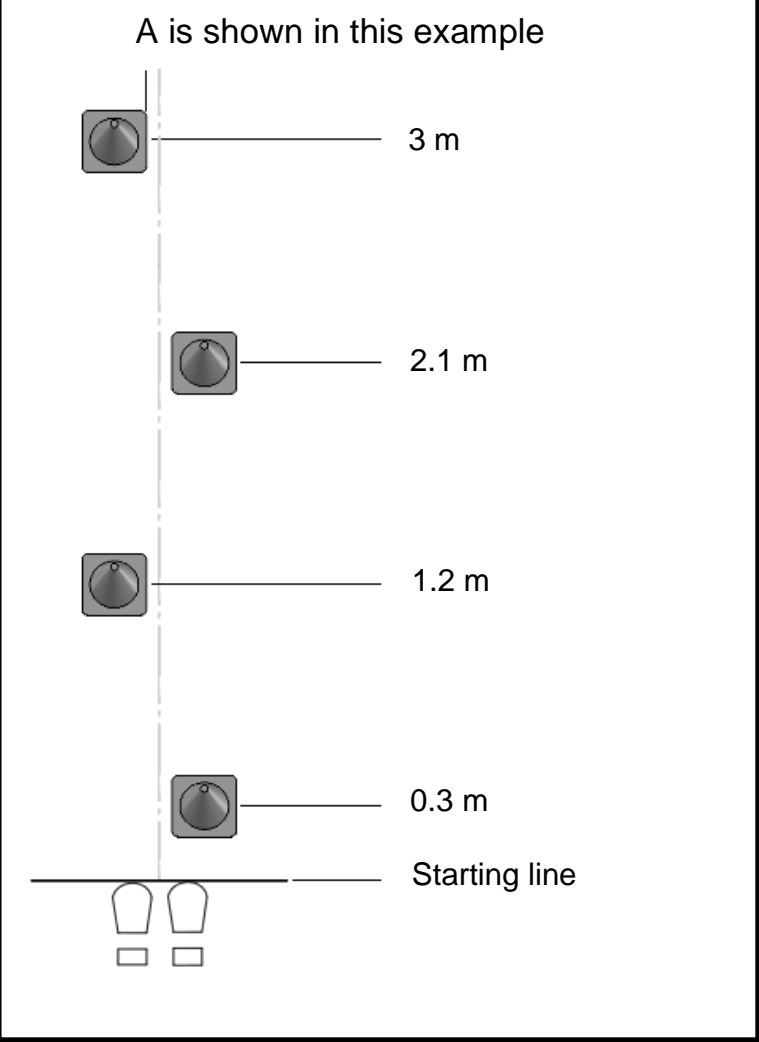

To repeat the test quickly, tape strips can be used to mark the floor.

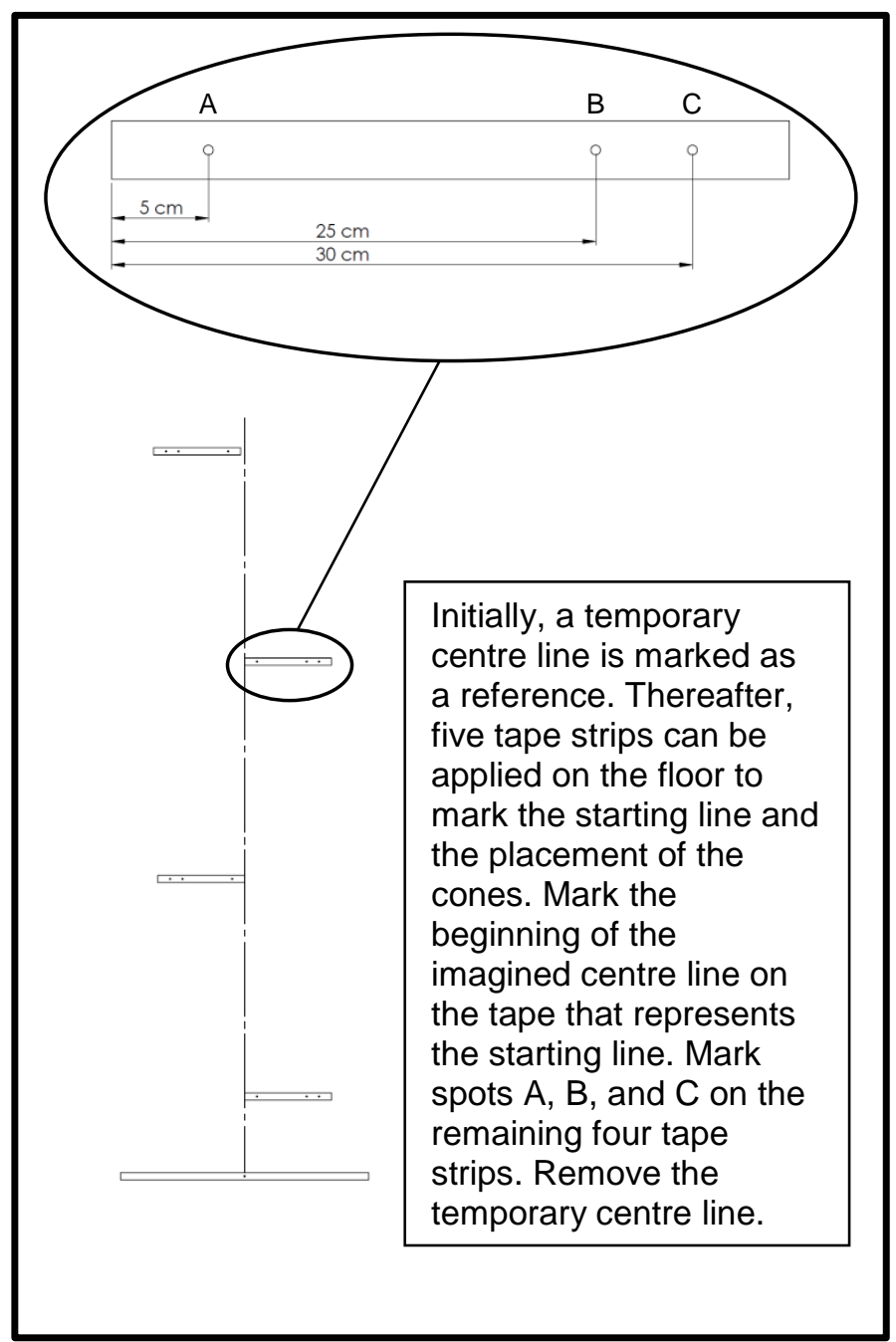

(A) Used when the subject walks without a walking aid or with crutches or a cane

(B) Used when the subject uses a walker

(C) Used when the subject uses a walking table

\section{Instructions}

Place the subject facing the imagined centre line, with the toes or the front of the walking aid at the starting line. If the subject walks with the support of another person, this must be noted in the protocol, and the subject must control the walk (as much as possible). The subject is instructed to complete the task twice. Record the total number of cones the subject touches. A cone is judged as touched regardless of whether the base or the cone itself is touched. The frame of a walker with legs is equivalent to the wheels on a walker or a walking table.

Subject instruction: Your task is to walk forward between the cones without touching them. You will need to swerve to avoid touching the cones. (Make sure that you do not touch the cones with either the front or the back wheels of your walking aid.) 


\section{Test protocol CEW}

Use the picture below to record which cones the subject touches. Next to each cone, write "F" if the cone is touched with a front wheel, " $B$ " if it is touched with a back wheel, and " $X$ " if the subject touches the cone while walking without a walking aid, or if the cone is touched by the subject's crutches or cane. If the subject touches a cone with both the front and the back wheel, only the front wheel is noted. If the walking device has a frame between front and back wheels, everything behind the front wheel is judged as the back wheel. If there are any doubts in the assessment, the cone should not be judged as touched.
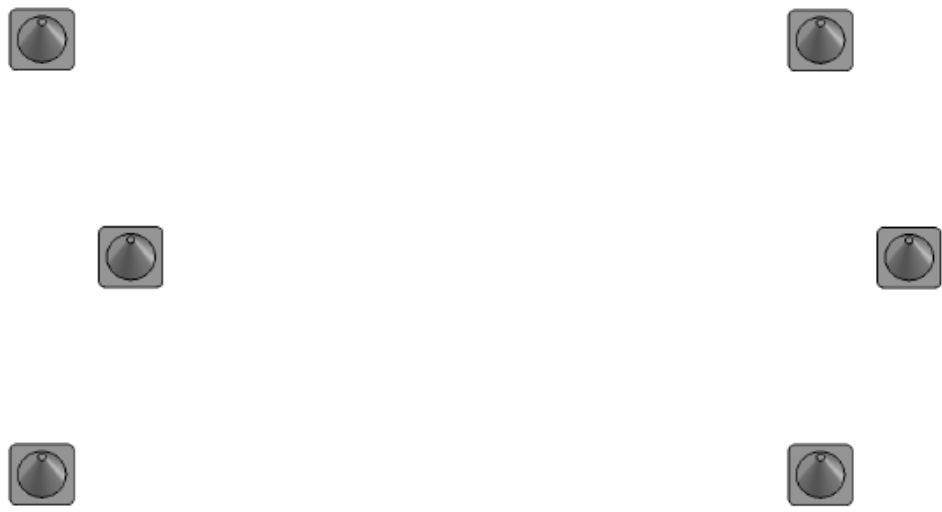

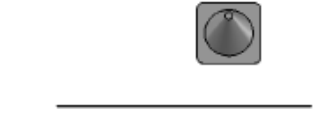

The first 3-metre walk
The second 3-metre walk

Summarise the number of cones touched below (possible outcomes $0-4$ touched cones on the left and $0-4$ touched cones on the right).

The total number of cones touched on the left: (with or without a walking aid) including with the front wheel and with only the back wheel (where applicable)

The total number of cones touched on the right: (with or without a walking aid) including with the front wheel and with only the back wheel (where applicable)

Total score (left + right):

Walking aid used:

$\square$ supervision necessary

$\square$ physical support by person(s)

Subject: Date:

Sjöholm H, Hägg S, Nyberg L, Rolander B, Kammerlind AS. The Cone Evasion Walk test: Reliability and validity in acute stroke. Physiother Res Int. 2019;24(1):e1744. doi: 10.1002/pri.1744 